\title{
Within-season sequential density dependence regulates breeding success in mallards Anas platyrhynchos
}

\author{
Johan Elmberg, Gunnar Gunnarsson, Hannu Pöysä, Kjell Sjöberg and Petri Nummi
}

\begin{abstract}
Elmberg, J., Gunnarsson, G., Pöysä, H., Sjöberg, K. and Nummi, P. 2005. Withinseason sequential density dependence regulates breeding success in mallards Anas platyrhynchos. - Oikos 108: 582-590.
\end{abstract}

\begin{abstract}
Density dependence in vital rates is a key issue in population ecology but remains largely unexplored experimentally. We studied breeding success, lake use, and prey availability in wild mallards Anas platyrhynchos on small nemoral lakes in a replicated, two-year cross-over experiment in which pair density was increased. The number of wild mallards that settled on lakes prior to introductions of extra pairs did not differ between control and introduction years. Introductions led to a lake-level reduction in the number of broods observed. However, the number of stage $2+$ (almost fledged) ducklings did not differ between treatments, nor did lake utilization by nonbreeding adults, broods and ducklings. Prey resource availability differed greatly among lakes, but it did not correlate with breeding success. Partialling out the possible effect of food competition from wild adult nonbreeding mallards did not change this conclusion. Our study demonstrates sequential density dependence in breeding success; introductions caused a decrease in brood number, but despite fewer broods a similar number of nearly fledged ducklings were produced. We suggest that predation and/or lake change of broods soon after hatching created these patterns. We conclude that using a single and late measure of breeding success such as fledged birds can mask regulatory processes. Implications of density dependence and its relation to individual reproductive success are understood better if breeding success is decomposed into nest success, duckling survival and fledgling survival.
\end{abstract}

J. Elmberg and G. Gunnarsson, Dept of Mathematics and Natural Sciences, Kristianstad Univ., SE-291 88, Kristianstad, Sweden (johan.elmberg@mna.hkr.se). - GG and K. Sjöberg, Dept of Animal Ecology, Swedish Univ. of Agricultural Sciences, SE-901 83, Umeà, Sweden. - H. Pöysä, Finnish Game and Fisheries Research Institute, Joensuu Game and Fisheries Research, Kauppakatu 18-20, FIN-80100, Joensuu, Finland. - P. Nummi, Dept of Applied Biology, Univ. of Helsinki, P.O. Box 27, FIN-00014, University of Helsinki, Finland.

More than two hundred years after Malthus (1798) and seventy years after Nicholson (1933), density dependence and regulation of populations remain central issues in ecology. One reason is the fundamental theoretical importance of these processes to the understanding of temporal trajectories and spatial dynamics of populations (Royama 1992, Cappuccino and Price 1995, Amarasekare 2004). Another reason is that applied ecology is increasingly being involved in the management of endangered, harvested and otherwise exploited populations (Albon et al. 2000, Bradbury et al. 2001, Webster 2003, Kjellander et al. 2004). There is ample empirical evidence that density-related feedback on birth and death rates does occur in natural populations. However, density dependence remains controversial when it comes to terminology and how to best detect it (Shenk et al. 1998, Turchin 1999, White 2001, Berryman et al. 2002). Further, the prevalence and impact of density dependent processes on population size remain unclear in most species where the topic has 
indeed been explored (Turchin 1995, Newton 1998, Sibly and Hone 2002, cf. Lima and Jaksic 1998). Clearly, more experimental research on demographic mechanisms of population regulation is needed (Dobson and Oli 2002).

Also in such well studied birds as dabbling ducks (Anas spp.), there is conflicting evidence whether population sizes are mainly determined by density independent factors such as summer drought and winter cold, or by potentially density dependent factors like breeding success and mortality (Trost et al. 1993, Sheaffer 1998, Miller 2000, Johnson et al. 2002). As in voles, songbirds, and many other taxonomic groups, positive evidence for density dependence in waterfowl generally stems either from analyses of long term data or from correlations between population size and recruitment or mortality (Hill 1984a, Vickery and Nudds 1984, Kaminski and Gluesing 1987, Nichols 1991, Sheaffer 1998, Elmberg et al. 2003, Pöysä and Pesonen 2003). Despite recurrent calls for a more manipulative and experimental approach in population ecology, i.e. a shift in emphasis from pattern-oriented to process-oriented studies (Harrison and Cappuccino 1995, Coulson et al. 2000), neither natural patterns found nor model predictions produced by waterfowl studies have been tested experimentally.

Another and general ecological issue is whether density dependence is looked for at the most relevant spatial and demographic scales (Ray and Hastings 1996, Newton 1998, Grimm and Uchmanski 2002, Wauters et al. 2004). Most studies of density dependence in waterfowl have been carried out at large spatial scales, where there is little chance of detecting density dependent patterns occurring at the lake level, and where overall recruitment is measured and no attention is paid to differences in fitness between individuals (GossCustard and Sutherland 1997, Durell et al. 2000). Until recently (Elmberg et al. 2003) there have been few attempts - none in waterfowl - to replace the traditional 'individuals per area' measure of density with more relevant counterparts. As has been noted repeatedly (Newton 1998 pp. 115-119, White 2001) area per se is not necessarily a limited resource for which competition is likely; it is merely a proxy for density measures such as per capita abundance of food and nest sites.

Food is a key resource in breeding mallards Anas platyrhynchos L., as shown by a general positive association between abundance of invertebrate prey and duckling growth and survival rates (Street 1977, Sedinger 1992, Cooper and Anderson 1996, Cox et al. 1998). Although food limitation may occur on at least some boreal lakes there is no evidence for density dependent breeding success in mallards on them (Pöysä et al. 2000, Sjöberg et al. 2000, Pöysä 2001, Elmberg et al. 2003). In contrast, some studies of mallards on nemoral lakes have reported density dependent breeding success (Kaminski and Gluesing 1987, Sheaffer 1998, Elmberg 2003).

The mallard is the world's most abundant dabbling duck and also one of the most studied game species globally. Despite intensive research, remarkably little is still known about the prevalence and role of density dependent population processes in this species. We concur with Kaminski and Gluesing (1987), Clark and Nudds (1991), Nichols (1991), Both (1998) and Sheaffer (1998) that one reason for this is a paucity of experiments. In studies of other species where large scale density manipulations have indeed been made (e.g. nest box studies reviewed by Newton 1998; culled roe deer in Kjellander et al. 2004), there is a general lack of replication, few examples of cross-over design, and only rarely any effort to control for difference in individual quality of putative competitors.

We here address these shortcomings in a replicated, lake-level, cross-over study of wild mallard pairs and broods facing known food abundance and randomly selected introduced conspecific competitors, all on similar natural lakes in a restricted geographical area. We test the hypothesis that breeding success is negatively density dependent, predicting that success should decrease with increasing lake-level population density. Lake-level predictions were that wild mallards would respond to introduction by having fewer broods, raising fewer ducklings, and decreasing lake utilization. We also measured food abundance and tested whether it was positively correlated to breeding success.

\section{Methods}

\section{Study area}

In 2000 we did a pre-experiment baseline study of 27 small lakes $(0.2-6.3 \mathrm{ha})$ in Scania, southernmost Sweden, comprising four pair counts (18 March-8 May) and seven brood counts (12 May-17 July). Sixteen of the 27 lakes were selected for experiments in 2001-2002 (Table 1), and they shared the following characteristics: 1) mallard bred or were seen regularly during the breeding season in 2000,2$)$ none had more than two breeding species of dabbling duck in 2000,3) none hosted large numbers of transient staging ducks, 4) there were no other lakes or wetlands within one kilometer unless they too were part of the study; i.e. possible between-lake movements were likely to be detected, 5) none hosted feral waterfowl, 6) none had significant human disturbance (fishing, swimming, boating), 7) all were mesotrophic - eutrophic, 8) the entire lake was visible from one or two concealed vantage points, and 9) emergent vegetation did not prevent efficient waterfowl surveys. Lakes selected represent the local landscape composition; nine were situated in open farmland or 
Table 1. Name, location (latitude, longitude), census cluster, area (hectares), and experimental treatment of study lakes.

\begin{tabular}{|c|c|c|c|c|c|}
\hline Lake & Location & Cluster & Area & 2001 & 2002 \\
\hline Bolshög & $55^{\circ} 31.00 \mathrm{~N} 14^{\circ} 14.71 \mathrm{E}$ & 1 & 0.8 & control & introduction \\
\hline Alenäs & $55^{\circ} 39.46 \mathrm{~N} 14^{\circ} 13.00 \mathrm{E}$ & 1 & 0.7 & control & introduction \\
\hline Torup O & $55^{\circ} 42.19 \mathrm{~N} 14^{\circ} 10.94 \mathrm{E}$ & 1 & 2.3 & control & introduction \\
\hline Torup V & $55^{\circ} 42.18 \mathrm{~N} 14^{\circ} 10.75 \mathrm{E}$ & 1 & 0.8 & control & introduction \\
\hline N Vitemölla & $55^{\circ} 42.27 \mathrm{~N} 14^{\circ} 11.85 \mathrm{E}$ & 1 & 0.7 & control & introduction \\
\hline N Lökaröd NV & $55^{\circ} 48.34 \mathrm{~N} 14^{\circ} 06.38 \mathrm{E}$ & 2 & 1.4 & control & introduction \\
\hline Lyngsiön & $55^{\circ} 55.89 \mathrm{~N} 14^{\circ} 04.13 \mathrm{E}$ & 3 & 6.3 & control & introduction \\
\hline Karpalund NO & $56^{\circ} 02.84 \mathrm{~N} 14^{\circ} 05.96 \mathrm{E}$ & 3 & 3.7 & control & introduction \\
\hline O Hercules & $56^{\circ} 00.32 \mathrm{~N} 14^{\circ} 16.08 \mathrm{E}$ & 3 & 0.2 & control & introduction \\
\hline Ravlunda & $55^{\circ} 42.97 \mathrm{~N} 14^{\circ} 08.85 \mathrm{E}$ & 1 & 0.8 & introduction & control \\
\hline Öståkra & $55^{\circ} 44.73 \mathrm{~N} 14^{\circ} 09.38 \mathrm{E}$ & 1 & 0.6 & introduction & control \\
\hline O N Lökaröd & $55^{\circ} 47.92 \mathrm{~N} 14^{\circ} 07.99 \mathrm{E}$ & 2 & 0.6 & introduction & control \\
\hline N Lökaröd NO & $55^{\circ} 48.37 \mathrm{~N} 14^{\circ} 06.47 \mathrm{E}$ & 2 & 0.9 & introduction & control \\
\hline Degeberga & $55^{\circ} 49.84 \mathrm{~N} 14^{\circ} 05.19 \mathrm{E}$ & 2 & 2.2 & introduction & control \\
\hline Karpalund NV & $56^{\circ} 02.81 \mathrm{~N} 14^{\circ} 05.77 \mathrm{E}$ & 3 & 3.9 & introduction & control \\
\hline Karpalund SV & $56^{\circ} 02.77 \mathrm{~N} 14^{\circ} 05.79 \mathrm{E}$ & 3 & 0.4 & introduction & control \\
\hline
\end{tabular}

pastures, three were in forest, and four in the ecotone between forest and farmland.

The study area is at the northern edge of the nemoral vegetation zone and has a sub-Atlantic climate with a protracted nesting season for waterfowl. Although most mallards and some of the other breeding waterfowl species can be assumed to winter locally (Fransson and Pettersson 2001), all study lakes were ice-covered for 2-6 weeks in both winters preceding experimental treatment. Most breeding species, including mallards, were present on the study lakes by mid March in both experiment years. Initiation of primary nests generally occur in late April or early May (Results).

\section{Survey procedures 2001-2002}

Each study lake was visited weekly during the breeding season to conduct two pair counts (23 April-2 May) and 12 brood counts (10 May-21 July). Pair and brood counts were done according to the point count method in Koskimies and Pöysä (1991), with the following adjustments. Pair counts were done as three thorough scans of the entire lake with a 5-10 min pause between scans. A brood count was a $30 \mathrm{~min}$ continuous observation period. Lakes were visited any time from $30 \mathrm{~min}$ after sunrise until $30 \mathrm{~min}$ before sunset. Exceptionally windy, rainy, cold, and hot weather was avoided, resulting in brood counts in June and July primarily being done in the morning and in the evening. Visit order was randomized among the three geographical clusters of study lakes (Table 1), but within clusters it was randomized in sequence only (i.e. "forward" or "backward").

Head markings and bill patterns of all adult female mallards were noted in detail: a) length, width and color of subocular, ocular and supraocular stripes, b) amount of streaking on crown and throat, c) absence/presence of loral patch, d) extent and color of light lower bill edge, e) amount and color of dark bill spots, and f) other peculiarities in body plumage and feather wear. This permitted positive individual recognition on most survey occasions, and it was of great help in reconstructing brood history and detecting between-lake movements where possible. Ducklings were aged (below) using the classification by Pirkola and Högmander (1974), which is a combination of schemes in Gollop and Marshall (1954) and Linkola (1962). All waterfowl counts were made by JE.

\section{Release of wingclipped mallards}

Wildstrain mallards were purchased from a local game farm, where they had been kept over winter in a common pen and fed ad libitum to reduce individual differences in body condition. Two males and two females were randomly selected from a large pool of birds, and released onto each introduction lake after pair counts and prior to the first brood count (4 May in 2001 and 9 May in 2002; see Table 1 for lake-level treatment in different years). At this time most local wild females were nesting, and no wild broods had yet hatched (estimated median hatch date was 4 June in 2001 and 18 June in 2002, respectively). Released birds were wingclipped on one side, thus flightless, and it was possible to identify them as introduced at a distance due to the lack of primary projection on the closed wing. Molt was later in introduced mallards than in wild; hence wild and introduced birds were safely separable until the last week of June or early July, depending on lake and year. As most study lakes had only one or two breeding pairs of wild mallards, introduction effectively increased the operational population density.

\section{Prey abundance and indices}

Aquatic prey was sampled 21-25 May 2001, and 28-31 May 2002, when we assumed there would be a peak in 
broods aged 1-12 days (but see median hatch date above). This is when duckling mortality is the highest and when they are most dependent on animal food (Talent et al. 1983, Hill et al. 1987, Orthmeyer and Ball 1990, Rotella and Ratti 1992a, Mauser et al. 1994). We used submerged activity traps similar to Murkin et al. (1983), with a one liter glass jar and a small entrance funnel (100 mm diameter at the wide end and $23 \mathrm{~mm}$ at the narrow). Such traps catch benthic, nektonic, as well as hatching metamorphosing invertebrates. They are thus to be preferred before emergence traps, which give a taxonomically more restricted catch and which may introduce a sampling bias if the timing of insect emergence differs among lakes. In each lake we placed eight to ten traps horizontally in the littoral zone, in or at the edge of aquatic vegetation. Traps were three meters apart, one meter from the shore, and $10-40 \mathrm{~cm}$ deep. Each trap was operated for $48 \mathrm{~h}$, after which contents were passed through a $1 \mathrm{~mm}$ mesh sieve. Prey were counted and identified to the taxonomic groups in Table 2 of Nudds and Bowlby (1984), with amphibian larvae, invertebrate eggs, and turbellarians as added taxa. Following the same authors, each item was also assigned to a length class $(1-2.5,2.6-7.5,7.6-12.5,12.6-20$, 21-40, 41-60, and $>60 \mathrm{~mm}$ ). Contents of each trap were analyzed separately. Prey sampling was not possible in one lake (N Vitemölla) in 2001.

While in development stages $1 \mathrm{a}-1 \mathrm{~b}$ (i.e. 1-14 days old; Schemnitz 1980) mallard ducklings mainly eat small invertebrates on the water surface, but they also forage on land and from emergent aquatic plants (Chura 1961, Collias and Collias 1963, Pehrsson 1979, Reinecke 1979, Sedinger 1992). Taxonomic selectivity at this age is low (Cramp and Simmons 1977, Krapu and Swanson 1977, Street 1977, Reinecke 1979), although dipterans (especially hatching Chironomidae) are often very important prey (Bengtson 1975, Dzus and Clark 1997).
There are no published data about prey size selectivity in young ducklings, but Olney (1964) found that adult mallards in winter chiefly consume items in the $1-10$ $\mathrm{mm}$ range. Based on this dietary information we constructed an index to reflect prey availability for young ducklings in each lake. We used data on prey in size classes 1-3 (1-12.5 mm), but hard-shelled Dytiscidae and other Coleoptera were represented by items $<7.5 \mathrm{~mm}$ only. Weighting by size was done such that the total number of prey in each size class was multiplied by the mid value of that size class (i.e. 1.75, 5.1, and $10 \mathrm{~mm}$ ). These products were then added, and the sum was standardized to "per 100 trap days".

\section{Definition of dependent variables}

"Number of broods hatched" is the number of broods observed and actually hatched at a lake; thus a brood that changed lakes was assigned only to its lake of origin. "Number of age class $2+$ ducklings produced" refers to ducklings older than 19-21 days (Gollop and Marshall 1954, Schemnitz 1980). When there were multiple observations of a brood in stage 2 a or older, we used data from the latest sighting before fledging. However, if fledglings but not stage 3 ducklings were seen, the number of fledglings on a lake was used. Ducklings were assigned to the lake where they were detected at first sighting in stage $2 \mathrm{a}-2 \mathrm{c}$, regardless of origin. "Adult days" is assumed to reflect how much a lake was used by wild mallards. This variable only concerns adults observed after the introduction of wingclipped birds. Females with broods were excluded to avoid intercorrelation with "brood days" below. Each bird on each brood count day scored one point, i.e. the final value is a combination of the number of individuals and how many times they were seen on a lake. Moulting birds that could

Table 2. Breeding success (broods and ducklings of age class $2+$ observed) and lake utilization (lake use days by non-breeding adults, broods, and ducklings) of wild mallards on study lakes where experimental introduction succeeded. Control and introduction years are detailed in Table 1 .

\begin{tabular}{|c|c|c|c|c|c|c|c|c|c|c|}
\hline \multirow[t]{2}{*}{ Lake } & \multicolumn{2}{|c|}{ Broods } & \multicolumn{2}{|c|}{ Ducklings $2+$} & \multicolumn{2}{|c|}{ Adult days } & \multicolumn{2}{|c|}{ Brood days } & \multicolumn{2}{|c|}{ Duckling days } \\
\hline & control & introduction & control & introduction & control & introduction & control & introduction & control & introduction \\
\hline Bolshög & 1 & 1 & 8 & 6 & 47 & 17 & 1 & 2 & 6 & 12 \\
\hline Alenäs & 0 & 0 & 0 & 0 & 1 & 4 & 0 & 0 & 0 & 0 \\
\hline Torup O & 1 & 2 & 6 & 14 & 16 & 38 & 5 & 13 & 32 & 96 \\
\hline Torup V & 1 & 0 & 6 & 0 & 32 & 3 & 5 & 0 & 31 & 0 \\
\hline N Vitemölla & 1 & 0 & 5 & 0 & 8 & 9 & 3 & 0 & 13 & 0 \\
\hline N Lökaröd NV & 1 & 0 & 0 & 0 & 5 & 3 & 1 & 0 & 10 & 0 \\
\hline Lyngsjön & 0 & 0 & 0 & 0 & 44 & 10 & 0 & 0 & 0 & 0 \\
\hline O Hercules & 1 & 0 & 9 & 0 & 25 & 26 & 1 & 0 & 9 & 0 \\
\hline Ravlunda & 1 & 0 & 0 & 0 & 30 & 7 & 2 & 0 & 10 & 0 \\
\hline Öståkra & 1 & 1 & 0 & 2 & 22 & 13 & 1 & 3 & 7 & 6 \\
\hline O N Lökaröd & 2 & 1 & 7 & 0 & 8 & 7 & 10 & 1 & 40 & 6 \\
\hline N Lökaröd NO & 1 & 0 & 0 & 9 & 17 & 21 & 2 & 2 & 4 & 19 \\
\hline Degeberga & 3 & 2 & 0 & 6 & 216 & 133 & 2 & 4 & 6 & 21 \\
\hline Mean & 1.08 & 0.54 & 3.15 & 2.85 & 36.15 & 22.19 & 2.54 & 1.92 & 12.92 & 12.31 \\
\hline Median & 1 & 0 & 0 & 0 & 22 & 9.5 & 2 & 0 & 9 & 0 \\
\hline Interquartile & 0 & 1 & 6.5 & 64 & 29.75 & 18.25 & 3 & 2.5 & 17 & 15.5 \\
\hline
\end{tabular}


not be classified as wild or introduced were counted as half an individual on introduction lakes. "Brood days" is the cumulative use of a lake by broods, i.e. each brood on each survey day scored one point. Origin of brood was not considered, i.e. it may have come from a neighboring lake. "Duckling days" is the cumulative use by ducklings of a lake; each duckling scored one point on each survey day that it was seen on a lake. Ducklings of all ages were included, and their lake of origin (hatching lake) was not taken into account.

The first two dependent variables are standard indices in waterfowl studies, referring to nesting success and recruitment, respectively. The three latter ones describe lake use in a more general sense. For each there is one value per lake and year, i.e. one from the control and one from the introduction treatment. We hypothesized that all five variables would show a negative response to the introduction, that is, predictions were directional.

\section{Statistical analyses}

All variables were nonnormally distributed (Lilliefors test, $\mathrm{P}<0.02$ ) and had unequal variances; hence nonparametric methods were used throughout. The Wilcoxon paired sample test was used to compare control and introduction treatments; sample sizes varied because tied pairs were ignored in some tests (Zar 1996). Probabilities (according to Zar 1996) are two-tailed unless explicitly directional predictions were made.

\section{Results}

\section{Success of mallard introductions}

When released, introduced birds quickly sought cover, and after less than one hour many were seen feeding like wild mallards. During the first month the behavior of introduced birds was indistinguishable from that of wild, and they often foraged and rested in the same places. Later on, as breeding of wild birds progressed with pair bonds weakening and males becoming less present or exposed, introduced birds instead often remained paired or in a group of four. Aggression between introduced birds and wild broods or their hen was never observed. Although copulation was observed among introduced birds, no female was recorded to breed successfully. Five cases of pairing between introduced females and wild males were observed, but with one exception these alliances never lasted more than one week.

Introduction was considered successful if at least three released birds remained on the lake for at least two weeks. Twice this criterion was not met, i.e. at Karpalund SV in 2001 and Karpalund NO in 2002. Unfortunately, the introduced mallards on the latter lake moved to a third lake (Karpalund NV, which was a control that year), further reducing sample size. Hence, all analyses and conclusions below refer to the remaining 13 lakes ("post-introduction" values given in Table 2). Most introduced birds remained on their lake for a very long time; of 64 birds released, a minimum of 47 were still on their lake after one month and at least 34 after two months. Only one bird was found dead and only eight did positively leave their introduction lake (seen nearby).

\section{Breeding success and lake use in wild mallards}

The number of wild mallard pairs settling to breed on the lakes did not differ between control and introduction years (control: mean $=2.1, \mathrm{SD}=2.8$, range $0-10$; introduction: mean $=2.2, \mathrm{SD}=1.6$, range $0-7 ; \mathrm{T}=28.0$, $\mathrm{P}>0.20, \mathrm{~N}=13$ lakes with successful introduction). Introductions had a negative effect on the number of broods hatched $(\mathrm{T}=5.0$, one-tailed $\mathrm{P}=0.025, \mathrm{~N}=9$ ), but none on the number of stage $2+$ ducklings $(\mathrm{T}=21.5$, one-tailed $\mathrm{P}>0.25, \mathrm{~N}=9$, data in Table 2). Nine of the 13 lakes with successful introduction were effectively isolated, hence there were no adjacent wetlands on which broods can have survived. Two pairs of study lake were close enough to permit inter-wetland travel within each pair; in 2001 one age class 1a brood moved from lake $\mathrm{N}$ Lökaröd NV (control that year) to N Lökaröd NO (introduction), but left the latter lake within two weeks not to be resighted on either. No other instance of a brood changing lakes was recorded. Lake use by nonbreeding adult mallards $(\mathrm{T}=23.0$, one-tailed $\mathrm{P}>0.05, \mathrm{~N}=13)$, broods $(\mathrm{T}=21.0$, one-tailed $\mathrm{P}>0.25$, $\mathrm{N}=10)$ and ducklings $(\mathrm{T}=28.0$, one-tailed $\mathrm{P}>0.25$, $\mathrm{N}=11$ ) did not differ between introduction and control treatment.

\section{Prey abundance}

Despite the overall similarity of study lakes (selection criteria under "Study area" in "Methods"), indices of prey abundance differed greatly (Fig. 1). In 2001 the richest lake had a value 187 times higher than that of the poorest. Prey abundance differed neither between calendar years in lake-level pair wise tests $(\mathrm{T}=34, \mathrm{P}>0.50$, $\mathrm{N}=12$ ), nor between control and introduction years $(\mathrm{T}=22, \mathrm{P}>0.20, \mathrm{~N}=12)$.

To explore whether patterns of breeding success in the introduction experiment were affected by a lake-level effect of prey abundance (Cox et al. 1998) we made two pairwise sets of rank correlations. For each lake, the number of broods hatched in the introduction year was subtracted from the number hatched in the control year, and this difference was correlated against the prey index value in the control year minus the prey index value in the introduction year. Second, the number of $2+$ ducklings produced in the introduction year was 
subtracted from the number of $2+$ ducklings produced in the control year, and this difference was correlated against the difference of prey index values as above. If food abundance does affect breeding success at the lake level we predicted a positive correlation in both cases; however; there was none (number of broods: $r_{\mathrm{s}}=-0.09$, $\mathrm{P}>0.3, \mathrm{~N}=12$; number of $2+$ ducklings: $\mathrm{r}_{\mathrm{s}}=-0.41$, $\mathrm{P}>0.05, \mathrm{~N}=12$; one-tailed probabilities due to directional predictions). This pattern persists also after controlling for the possible effect of competition with adult nonbreeding mallards (partial correlation coefficients with prey index after removing the effect of utilization days of wild and introduced birds: number of broods: $r_{p}=-0.20, P>0.25$; number of $2+$ ducklings: $\mathrm{r}_{\mathrm{p}}=-0.45, \mathrm{P}>0.05 ; \mathrm{N}=12$; one-tailed probabilities). In 2001, no other dabbling ducks bred on the study lakes, and in 2002 only one pair of garganey Anas querquedula L., a much smaller species and a late nester, bred on one of them. Hence, other dabbling ducks were considered unimportant to mallard breeding success in this study.

\section{Discussion}

Breeding success must have been subject to two density dependent episodes, the first occurring during nesting or the first days after hatching. We think there are two possible explanations, which are not necessarily mutually exclusive. The first is predation - on eggs, incubating hens or newly hatched ducklings. Predators may have been attracted by and responded to the experimentally increased mallard density, i.e. a functional or numerical response increasing the per capita predation rate (Tinbergen et al. 1967). Predation is a realistic scenario also based on previous studies demonstrating high nest predation rates (Weller 1979, Hill 1984a, b, Sugden and Beyersbergen 1986, Andrén 1991, Esler and Grand 1993, Larivière and Messier 1998). The alternative explanation for the reduction in the number of broods observed is that wild females left the lake in response to the introduction, either early to re-nest elsewhere or later with their brood. Other studies have shown that inter-wetland movements of mallard hens with brood may be common and may occur soon after hatching (Talent et al. 1982, Rotella and Ratti 1992b, Dzus and Clark 1997). Our study was not designed to discriminate between these two scenarios, but the lakes were indeed isolated from other wetlands, and the only recorded case of inter-wetland travel was apparently not successful (Results). Either way, both mechanisms involve responses to experimentally increased density.

Our cross-over design makes the possibility of a between-year bias in clutch size very unlikely. Hence, the second density dependent process must have operated during the brood stage, as a similar number of pairs produced fewer broods but a similar number of $2+$ ducklings. We predicted that food abundance limits brood and duckling survival (cf. Street 1977, p. 124), but prey index data did not support this idea. Although reports from a variety of environments have pointed out that food abundance, including emerging insects, is correlated to duckling foraging behavior and productivity (Danell and Sjöberg 1977, Hill et al. 1987, Sedinger 1992, Cox et al. 1998, Nummi et al. 2000), the lack of such a pattern here is perhaps not surprising. Most of our lakes are eutrophic and abundance of aquatic prey is very high, about 200 times higher than in Finnish lakes where Elmberg et al. (2003) found food-related density dependence in teal Anas crecca L. and wigeon Anas penelope $\mathrm{L}$. Apparently, some other factor regulated the number of ducklings. Previous studies have highlighted predation (Solman 1945), chilling (Koskimies and Lahti 1964), and disease (Sargeant and Raveling 1992), but our study was not designed to discriminate between these alternatives.

As the number of $2+$ ducklings produced did not differ between control and introduction treatments, it is logical that neither did the number of duckling days (Table 2). More counter-intuitive, though, is the lack of difference in brood days between treatments, but the proportional decrease in brood days from the control year to the introduction year was greater for brood days (ca 24\%) than for duckling days (ca 5\%). Most likely, some females with broods left the lakes soon after hatching and/or total brood loss occurred soon after hatching, both processes reducing the accumulation of brood days.

If we had measured breeding success only as the number of $2+$ ducklings produced, we would have concluded that it was unrelated to density. In other words, using a single and late measure of breeding success can mask density dependent processes that occur in sequence (Åström et al. 1996), especially if processes

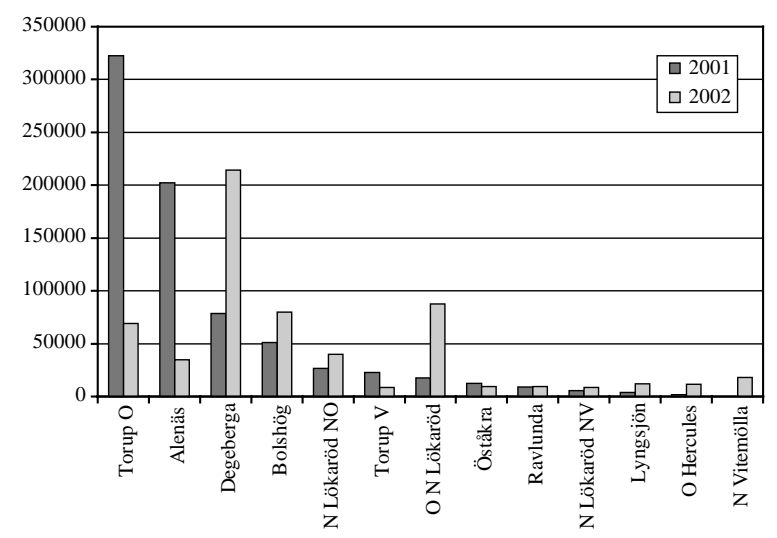

Fig. 1. Prey abundance in the study lakes in 2001-2002. Y axis values are indices, the calculation of which is described in Methods. 
are counteracting or if they are singularly weak but mutually reinforcing (Vonesh and De la Cruz 2002, Rodenhouse et al. 2003, Wauters et al. 2004). As far as we know, no waterfowl study to date has accounted for this possible bias (Trost et al. 1993, p. 109). For example, many North American duck population models relate the proportion of juveniles in fall to an estimate of breeding pairs over a larger area to infer density dependent recruitment (Kaminski and Gluesing 1987, Reynolds and Sauer 1991, Sheaffer 1998, Miller 2000). Though some of these studies indicate that recruitment is indeed density dependent (Kaminski and Gluesing 1987, Sheaffer 1998), the lack of such a pattern in others could be due to counteracting density dependent processes in earlier stages of the breeding season. Further, if sequential density dependence operates within the breeding season, the total number of fledglings per lake may be the same for different initial pair densities. Decomposing recruitment into components - nest success, duckling survival and fledgling survival - can reveal significant dynamics that may remain undetected if the end result only is measured (Pöysä and Pöysä 2002, Wauters et al. 2004).

This is one of very few experimental studies demonstrating a sequence of density dependent events during the breeding season in a bird (Newton 1998, pp. 110114, but see Rodenhouse et al. 2003). The significance of sequential density dependence has previously been emphasized from a theoretical perspective (Åström et al. 1996, Jonzén and Lundberg 1999), especially to organisms living in seasonal environments. Such sequential patterns have been thought to mainly concern processes occurring in different seasons (Hansen et al. 1999, Jonzén and Lundberg 1999, Albon et al. 2000, Yoccoz et al. 2001, Wauters et al. 2004). Åström et al. (1996) argue, though, that sequential density dependence may occur on a finer temporal scale; a view boldly supported by the present experiment, and also by some previous descriptive waterfowl studies (Larsson and Forslund 1994, Nummi and Saari 2003). Our pair density manipulation revealed regulation within the breeding season, notably a regulatory processes leading to a spurious end result of density independent breeding success. However, until more is known about the prevalence of density dependence in nest survival and in the survival of fledglings until they are recruited into the breeding population, the implications of the present experiment to mallard population dynamics and to harvest models remain speculative.

\footnotetext{
Acknowledgements - Per Lundberg, Niclas Jonzen, and Mårten Åström originally drew our attention to the lack of experimental studies in this field. Bob Clark gave valuable input to the manuscript. Kelly Squires and Celine Arzel assisted in collecting and processing invertebrate data. Hans Cronert and David Ståhlberg at the Scania County Administration Board provided maps and landowner information. Christer Alriksson at the Ravlunda Artillery Range made sure we survived fieldwork at Öståkra. We thank all landowners for access and cooperation.
}

Ducks were transported and released according to permit A1-02 from The Research Animal Ethics Board at the Court of Appeal for North Sweden, Umeå. The study was supported by grant V-124-01 from the Swedish Environment Protection Board to JE.

\section{References}

Albon, S. D., Coulson, T. N., Brown, D. et al. 2000. Temporal changes in key factors and key age groups influencing the population dynamics of female red deer. - J. Anim. Ecol. 69: $1099-1110$.

Amarasekare, P. 2004. The role of density-dependent dispersal in source-sink dynamics. - J. Theor. Biol. 226: 159-168.

Andrén, H. 1991. Predation: an overrated factor for overdispersion of birds' nests? - Anim. Behav. 41: 1063-1069.

Åström, M., Lundberg, P. and Lundberg, S. 1996. Population dynamics with sequential density-dependence. - Oikos 75 : 174-181.

Bengtson, S.-A. 1975. Food of ducklings of surface feeding ducks at lake Mývatn, Iceland. - Ornis Fenn. 52: 1-4.

Berryman, A., Lima Arce, M. and Hawkins, B. A. 2002. Population regulation, emergent properties, and a requiem for density dependence. - Oikos 99: 600-606.

Both, C. 1998. Experimental evidence for density dependence of reproduction in great tits. - J. Anim. Ecol. 67: 667-674.

Bradbury, R. B., Payne, R. J. H., Wilson, J. D. et al. 2001. Predicting population responses to resource management. - Trends Evol. Ecol. 16: 440-445.

Cappuccino, N. and Price, P. W. (eds) 1995. Population dynamics. New approaches and synthesis. - Academic Press.

Chura, N. J. 1961. Food availability and preferences of juvenile mallards. - Trans. N. Am. Wildlife Nat. Res. Conf. 26: $121-134$.

Clark, R. G. and Nudds, T. D. 1991. Habitat patch size and duck nesting success: the crucial experiments have not been performed. - Wildlife Soc. Bull. 19: 534-543.

Collias, N. E. and Collias, E. C. 1963. Selective feeding by wild ducklings of different species. - Wilson Bull. 75: 6-14.

Cooper, C. B. and Anderson, S. H. 1996. Significance of invertebrate abundance to dabbling duck brood use of created wetlands. - Wetlands 16: 557-563.

Coulson, T., Milner-Gulland, E. J. and Clutton-Brock, T. 2000. The relative roles of density and climatic variation on population dynamics and fecundity rates in three contrasting ungulate species. - Proc. R. Soc. Lond., Ser. B 267: $1771-1779$.

Cox, R. R., Hanson, M. A., Roy, C. C. et al. 1998. Mallard duckling growth and survival in relation to aquatic invertebrates. - J. Wildlife Manage. 62: 124-133.

Cramp, S. and Simmons, K. E. L. 1977. The birds of the Western Palearctic. Vol. 1. - Oxford Univ. Press.

Danell, K. and Sjöberg, K. 1977. Seasonal emergence of chironomids in relation to egglaying and hatching of ducks in a restored lake (northern Sweden). - Wildfowl 28: $129-135$.

Dobson, F. S. and Oli, M. K. 2002. The demographic basis of population regulation in Columbian ground squirrels. - Am. Nat. 158: 236-247.

Durell, Le V. dit S. E. A., Goss-Custard, J. D., Clarke, R. T. et al. 2000. Density-dependent mortality in Oystercatchers Haematopus ostralegus. - Ibis 142: 132-138.

Dzus, E. H. and Clark, R. G. 1997. Overland travel, food abundance, and wetland use by mallards: relationships with offspring survival. - Wilson Bull. 109: 504-515.

Elmberg, J. 2003. Density-dependent breeding success in mallards Anas platyrhynchos on a eutrophic lake. - Wildlife Biol. 9: 67-73. 
Elmberg, J., Nummi, P., Pöysä, H. et al. 2003. Breeding success of sympatric dabbling ducks in relation to population density and food resources. - Oikos 100: 333-341.

Esler, D. and Grand, J. B. 1993. Factors influencing depredation of artificial duck nests. - J. Wildlife Manage. 57: 244-248.

Fransson, T. and Pettersson, J. 2001. Svensk ringmärkningsatlas [Swedish bird ringing atlas]. Vol 1. - Ljungföretagen Tryckeri AB, Örebro, Sweden.

Gollop, B. and Marshall, W. H. 1954. A guide to aging duck broods in the field. - Mississippi Flyway Council Technical Section Report.

Goss-Custard, J. D. and Sutherland, W. J. 1997. Individual behaviour, populations and conservation. - In: Krebs, J. R. and Davies, N. B. (eds), Behavioral ecology: an evolutionary approach, 4th ed. Blackwell Science, pp. 373-395.

Grimm, V. and Uchmanski, J. 2002. Individual variability and population regulation: a model of the significance of withingeneration density dependence. - Oecologia 131: 196-202.

Hansen, T. F., Stenseth, N. C. and Henttonen, H. 1999. Multiannual vole cycles and population regulation during long winters: an analysis of seasonal density dependence. - Am. Nat. 154: 129-139.

Harrison, S. and Cappuccino, N. 1995. Using density-manipulation experiments to study population regulation. - In: Cappuccino, N. and Price, P. W. (eds), Population dynamics: new approaches and synthesis. Academic Press, pp. $131-147$.

Hill, D. A. 1984a. Population regulation in the mallard (Anas platyrhynchos). - J. Anim. Ecol. 53: 191-202.

Hill, D. A. 1984b. Clutch predation in relation to nest density in mallard and tufted duck. - Wildfowl 35: 151-156.

Hill, D. A., Wright, R. and Street, M. 1987. Survival of mallard ducklings Anas platyrhynchos and competition with fish for invertebrates on a flooded gravel quarry in England. - Ibis 129: $159-167$.

Johnson, F. A., Kendall, W. L. and Dubovsky, J. A. 2002. Conditions and limitations on learning in the adaptive management of mallard harvests. - Wildlife Soc. Bull. 30: $176-185$.

Jonzén, N. and Lundberg, P. 1999. Temporally structured density-dependence and population management. - Ann. Zool. Fenn 36: 39-44

Kaminski, R. M. and Gluesing, E. A. 1987. Density- and habitat-related recruitment in mallards. - J. Wildlife Manage. 51: $141-148$.

Kjellander, P., Hewison, A. J. M., Liberg, O. et al. 2004 Experimental evidence for density-dependence of homerange size in roe deer (Capreolus capreolus L.): a comparison of two long-term studies. - Oecologia 139: 478-485.

Koskimies, J. and Lahti, L. 1964. Cold-hardiness of the newly hatched young in relation to ecology and distribution in ten species of European ducks. - Auk 81: 281-307.

Koskimies, J. and Pöysä, H. 1991. Waterfowl point count. - In: Koskimies, P. and Väisänen, R. A. (eds), Monitoring bird populations. Zool. Mus., Finnish Mus. Nat. Hist., Helsinki, pp. $41-44$.

Krapu, G. L. and Swanson, G. A. 1977. Foods of juvenile, brood, hen, and post-breeding pintails in North Dakota. - Condor 79: 504-507.

Larivière, S. and Messier, F. 1998. Effect of density and nearest neighbours on simulated waterfowl nests: can predators recognize high-density nesting patches? - Oikos 83: $12-20$.

Larsson, K. and Forslund, P. 1994. Population dynamics of the barnacle goose Branta leucopsis in the Baltic area: densitydependent effects on reproduction. - J. Anim. Ecol. 63: 954-962.

Lima, M. and Jaksic, F. M. 1998. Population variability among three small mammal species in the semiarid Neotropics: the role of density-dependent and density-independent factors. - Ecography 21: 175-180.

Linkola, P. 1962. Havaintoja sorsalintujen lisääntymistuloksesta Keski-Hämessä. (English summary: Notes on the breeding success of ducks in central Häme). - Suomen Riista 15: $157-174$.

Malthus, T. R. 1798. An essay on the principle of population. - J. Johnson, London.

Mauser, D. M., Jarvis, R. L. and Gilmer, D. S. 1994. Survival of radio-marked mallard ducklings in northeastern California. - J. Wildlife Manage. 58: 82-87.

Miller, M. W. 2000. Modelling annual mallard production in the prairie-parkland region. - J. Wildlife Manage. 64: 561-575.

Murkin, H. R., Abbott, P. G. and Kadlec, J. A. 1983. A comparison of activity traps and sweep nets for sampling nektonic invertebrates in wetlands. - Freshw. Inv. Biol. 2: 99-106.

Newton, I. 1998. Population limitation in birds. - Academic Press.

Nichols, J. D. 1991. Extensive monitoring programmes viewed as long-term population studies: the case of North American waterfowl. - Ibis 133: 89-98.

Nicholson, A. J. 1933. The balance of animal populations. - J. Anim. Ecol. 2: 132-178.

Nudds, T. D. and Bowlby, J. N. 1984. Predator-prey size relationships in North American dabbling ducks. - Can. J. Zool. 62: 2002-2008.

Nummi, P. and Saari, L. 2003. Density-dependent decline of breeding success in an introduced, increasing mute swan population. - J. Avian Biol. 34: 105-111.

Nummi, P., Sjöberg, K., Pöysä, H. et al. 2000. Individual foraging behaviour indicates resource limitation: an experiment with mallard ducklings. - Can. J. Zool. 78: 18911895.

Olney, P. J. S. 1964. The food of mallard Anas platyrhynchos collected from coastal and estuarine areas. - Proc. Zool. Soc. Lond. 142: 397-418.

Orthmeyer, D. L. and Ball, I. J. 1990. Survival of mallard broods on Benton Lake National Wildlife Refuge in northcentral Montana. - J. Wildlife Manage. 54: 62-66.

Pehrsson, O. 1979. Feeding behaviour, feeding habitat utilization, and feeding efficiency of mallard ducklings (Anas platyrhynchos L.) as guided by a domestic duck. - Viltrevy 10: $193-218$.

Pirkola, M. K. and Högmander, J. 1974. Sorsapoikueiden iänmääritys. (English summary: The age determination of duck broods in the field). - Suomen Riista 25: 50-55.

Pöysä, H. 2001. Dynamics of habitat distribution in breeding mallards: assessing the applicability of current habitat selection models. - Oikos 94: 365-373.

Pöysä, H. and Pöysä, S. 2002. Nest-site limitation and density dependence of reproductive output in the common goldeneye Bucephala clangula: implications for the management of cavity-nesting birds. - J. Appl. Ecol. 39: 502-510.

Pöysä, H. and Pesonen, M. 2003. Density dependence, regulation and open-closed populations: insights from the wigeon, Anas penelope. - Oikos 103: 358-366.

Pöysä, H., Elmberg, J., Sjöberg, K. et al. 2000. Nesting mallards (Anas platyrhynchos) forecast brood-stage food limitation when selecting habitat: experimental evidence. - Oecologia 122: $582-586$

Ray, C. and Hastings, A. 1996. Density-dependence: are we searching at the wrong spatial scale? - J. Anim. Ecol. 65: $556-566$.

Reinecke, K. 1979. Feeding ecology and development of juvenile black ducks in Maine. - Auk 96: 737-745.

Reynolds, R. E. and Sauer, J. R. 1991. Changes in mallard breeding populations in relation to production and harvest rates. - J. Wildlife Manage. 55: 483-487.

Rodenhouse, N. L., Sillett, T. S., Doran, P. J. et al. 2003. Multiple density-dependence mechanisms regulate a migratory bird population during the breeding season. - Proc. R. Soc. Lond. B. 270: 2105-2110.

Rotella, J. J. and Ratti, J. T. 1992a. Mallard brood survival and wetland habitat conditions in southwestern Manitoba. - J. Wildlife Manage. 56: 499-507. 
Rotella, J. J. and Ratti, J. T. 1992b. Mallard brood movements and wetland selection in southwestern Manitoba. - J. Wildlife Manage. 56: 508-515.

Royama, T. 1992. Analytival population dynamics. - Chapman and Hall.

Sargeant, A. B. and Raveling, D. G. 1992. Mortality during the breeding season. - In: Batt, B. D. J., Afton, A. D., Anderson, M. G. et al. (eds), Ecology and management of breeding waterfowl. Univ. of Minnesota Press, Minneapolis, pp. 396-422.

Schemnitz, S. D. 1980. Wildlife management techniques manual. - Wildlife Society, Washington DC.

Sedinger, J. S. 1992. Ecology of pre-fledgling waterfowl. - In: Batt, B. D. J., Afton, A. D., Anderson, M. G. et al. (eds), Ecology and management of breeding waterfowl. Univ. of Minnesota Press, Minneapolis, pp. 109-127.

Sheaffer, S. E. 1998. Recruitment models for mallards in eastern North America. - Auk 115: 988-997.

Shenk, T. M., White, G. C. and Burnham, K. P. 1998. Samplingvariance effects on detecting density dependence from temporal trends in natural populations. - Ecol. Monogr. 68: $445-463$.

Sibly, R. M. and Hone, J. 2002. Population growth rate and its determinants: an overview. - Philos. Trans. R. Soc. Lond., B. 357: 1153-1170.

Sjöberg, K., Pöysä, H., Elmberg, J. et al. 2000. Response of mallard ducklings to variation in habitat quality - an experiment of food limitation. - Ecology 81: 329-335.

Solman, V. E. F. 1945. The ecological relations of pike (Esox lucius L.) and waterfowl. - Ecology 26: 157-170.

Street, M. 1977. The food of mallard ducklings in a wet gravel quarry, and its relation to duckling survival. - Wildfowl 28: $113-125$.

Sugden, L. G. and Beyersbergen, G. W. 1986. Effect of density and concealment on American crow predation of simulated duck nests. - J. Wildlife Manage. 50: 9-14.

Talent, L. G., Krapu, G. L. and Jarvis, R. L. 1982. Habitat use by mallard broods in South Central North Dakota. - J. Wildlife Manage. 46: 629-635.
Talent, L. G., Jarvis, R. L. and Krapu, G. L. 1983. Survival of mallard broods in south-central North Dakota. - Condor 85: 74-78.

Tinbergen, N., Impekoven, M. and Franck, D. 1967. An experiment on spacing-out as a defence against predation. - Behaviour 28: 307-321.

Trost, R., Dickson, K. and Zavaleta, D. 1993. Harvesting waterfowl on a sustained yield basis: the North American perspective. - IWRB Special Publication 26: 106-112.

Turchin, P. 1995. Population regulation: old arguments and a new synthesis. - In: Cappuccino, N. and Price, P. W. (eds), Population dynamics. New approaches and synthesis. Academic Press, pp. 19-40.

Turchin, P. 1999. Population regulation: a synthetic view. - Oikos 84: 153-159.

Vickery, W. L. and Nudds, T. D. 1984. Detection of densitydependent effects in annual duck censuses. - Ecology 65 : 96-104.

Vonesh, J. R. and De la Cruz, O. 2002. Complex life cycles and density dependence: assessing the contribution of egg mortality to amphibian declines. - Oecologia 133: 325-333.

Wauters, L. A., Matthysen, E., Adriaensen, F. et al. 2004. Within-sex density dependence and population dynamics of red squirrels Sciurus vulgaris. - J. Anim. Ecol. 73: $11-25$.

Webster, M. S. 2003. Temporal density dependence and population regulation in a marine fish. - Ecology 84: 623-628

Weller, M. W. 1979. Density and habitat relationships of bluewinged teal nesting in northwestern Iowa. - J. Wildlife Manage. 43: 367-374.

White, T. C. R. 2001. Opposing paradigms: regulation or limitation of populations? - Oikos 93: 148-152.

Yoccoz, N. G., Stenseth, N. C., Henttonen, H. et al. 2001. Effects of food addition on the seasonal density-dependent structure of bank vole Clethrionomys glareolus populations. - J. Anim. Ecol. 70: 713-720.

Zar, J. H. 1996. Biostatistical analysis, 3rd ed. - Prentice Hall. 